\title{
Personalized regulation of glioblastoma cancer stem cells based on biomedical technologies: From theory to experiment (Review)
}

\author{
IGOR BRYUKHOVETSKIY ${ }^{1,2}$, ARINA PONOMARENKO ${ }^{1,2}$, IRINA LYAKHOVA ${ }^{1}$, SERGEY ZAITSEV ${ }^{1}$, \\ YULIA ZAYATS $^{1}$, MARIA KORNEYKO ${ }^{1}$, MARINA ELISEIKINA ${ }^{2}$, POLINA MISCHENKO ${ }^{1,2}$, \\ VALERIE SHEVCHENKO ${ }^{1,3}$, HARI SHANKER SHARMA ${ }^{4}$, \\ ARUNA SHARMA $^{4}$ and YURI KHOTIMCHENKO ${ }^{1,2}$ \\ ${ }^{1}$ Far Eastern Federal University, Vladivostok 690091; ${ }^{2}$ National Scientific Center of Marine Biology of \\ Far Eastern Branch of The Russian Academy of Sciences, Vladivostok 690059; \\ ${ }^{3}$ N.N. Blokhin Russian Cancer Research Center, Moscow 115478, Russia; \\ ${ }^{4}$ International Experimental CNS Injury \& Repair (IECNSIR), \\ Department of Surgical Sciences, Anesthesiology \& Intensive Care Medicine, \\ University Hospital, Uppsala University, Uppsala SE-75185, Sweden
}

Received December 15, 2017; Accepted May 2, 2018

DOI: $10.3892 / \mathrm{ijmm} .2018 .3668$

\begin{abstract}
Glioblastoma multiforme (GBM) is one of the most aggressive brain tumors. GBM represents $>50 \%$ of primary tumors of the nervous system and $20 \%$ of intracranial neoplasms. Standard treatment involves surgery, radiation and chemotherapy. However, the prognosis of GBM is usually poor, with a median survival of 15 months. Resistance of GBM to treatment can be explained by the presence of cancer stem cells (CSCs) among the GBM cell population. At present, there are no effective therapeutic strategies for the elimination of CSCs. The present review examined the nature of human GBM therapeutic resistance and attempted to systematize and put forward novel approaches for a personalized therapy of GBM that not only destroys tumor tissue, but also regulates cellular signaling and the morphogenetic properties of CSCs. The CSCs are considered to be an informationally accessible living system, and the CSC proteome should be used as a target for therapy directed at suppressing clonal selection mechanisms and CSC generation, destroying CSC hierarchy, and disrupting the interaction of CSCs with their microenvironment and extracellular matrix. These objectives can be achieved through the use of biomedical cellular products.
\end{abstract}

Correspondence to: Professor Igor Bryukhovetskiy, Department of Fundamental Medicine, School of Biomedicine, Far Eastern Federal University, 8 Sukhanova Street, Vladivostok 690091, Russia E-mail: igbryukhovetskiy@gmail.com

Key words: glioblastoma multiforme, cancer stem cells, epithelialmesenchymal transition, proteome, secretome, biomedical cellular product

\section{Contents}

1. Introduction

2. Current state of knowledge and possible solutions

3. Complex therapy of glioblastoma and CSC protein targets

4. Biomedical cellular technologies in glioblastoma therapy

5. Conclusion

\section{Introduction}

Glioblastoma multiforme (GBM) is one of the most aggressive brain tumors. This tumor represents $>50 \%$ of primary tumors of the nervous system and $\sim 20 \%$ of intracranial neoplasms (1). The average incidence rate of GBM is 3.19 cases/100,000 individuals, and the median age of diagnosis is 64 years. The incidence of GBM is higher in men and individuals of the Caucasian race and non-Hispanic ethnicity. Standard treatments involve surgery, radiation, and chemotherapy; however, prognosis is generally poor with a median survival of 15 months (2). GBM resistance to treatment (3-5) can be explained by the presence of cancer stem cells (CSCs) among the GBM cell population.

CSCs are immortalized cells that are at the top of the GBM cellular population hierarchy, possessing the highest level of proliferation among all GBM cells (6). The patient's immune system does not detect CSCs, leaving them intact. They actively interact with the common pool of tumor cells recruited from the blood by non-tumor cells and pathologically altered extracellular matrix (7-8). Certain basic theories of carcinogenesis consider the appearance of CSCs as a result of pathological transformation of neural stem cells in the brain (9). However, unlike normal stem cells, CSCs have a much higher content of proteins associated with proliferation, migration, DNA repair, 
radiation and chemotherapy resistance, survival, invasion and aggression $(10,11)$.

At present, there are no effective therapeutic strategies for the elimination of CSCs. As such, this calls for systematic analysis of GBM treatment resistance mechanisms and development of novel methods for treatment directed not only at the total eradication of tumor cells, but also at the regulation of signaling and morphogenetic properties of CSCs. One of the most promising strategies is the implementation of post-genome technologies for personalized medication and use of new biomedical cellular agents. Thus, a comparative study of our own experimental results and previous published data was conducted in order to formulate a proteome-based regulation of CSCs in the complex treatment of GBM.

\section{Current state of knowledge and possible solutions}

Gliomas represent the largest group of primary brain tumors. According to the World Health Organization classification (4), gliomas with a high potential of successful treatment through surgery and up to 5-year survival rate are assigned a lower grade of malignancy (Grade I-II). A higher grade of malignancy (Grade III-IV) is typically assigned to gliomas with invasive growth, high resistance to radiation and chemotherapy, and a median survival of 1-3 years. GBM is classified as an astrocytoma with the highest grade of malignancy (Grade IV).

Advances in molecular medicine have allowed to distinguish between primary and secondary forms of GBM (12). The first type of tumor develops spontaneously, while the second results from the transformation of a glioma with a lower grade of malignancy. Molecular and genetic abnormalities serve a key role in this process (13). Apart from epidermal growth factor receptor (EGFR), phosphatase and tensin homolog gene (PTEN), $\beta$-catenin, SMO, PTCH, NF1 and NF2 gene mutations are also typical in GBM. Various prognostic markers have been identified in GBM, and these include the methylation status of the gene promoter for $\mathrm{O}^{6}$-methylguanine-DNA methyltransferase (MGMT), isocitrate dehydrogenase enzyme 1/2 (IDH1/2) mutation, EGFR overexpression and amplification, glioma-CpG island methylator phenotype, tumor protein (TP53) mutation and genetic losses of chromosomes (14).

Primary GBMs exhibit EGFR overexpression, phosphatase and tensin homolog gene (PTEN) mutations, loss of heterozygosity (LOH) 10q and p16 deletions, in addition to, less frequently, mouse doubleminute 2 (MDM2) amplification, high frequency of telomerase reverse transcriptase (hTERT) promoter mutations and absence of IDH1 mutation. The secondary GBM hallmarks include mutations of TP53, IDH1 and $\alpha$-thalassemia/mental retardation syndrome $\mathrm{X}$-linked. Additionally, secondary GBMs exhibit LOH 10q. GBM with oligodendroglial component occurs in younger patients and often contains TP53 mutations, IDH1 mutation and lack of EGFR amplification (14). These patients have been reported to exhibit longer survival as compared to other GBM patients, as well as to possess a lower frequency of PTEN deletions, and genetic heterogeneity. Primary GBM is characterized by gene methylation that is $50 \%$ lower than that in healthy brain tissue, which is caused by mutation in DNA methyltransferase genes. The hypomethylation level in secondary GBMs is higher in comparison with that in the primary mode. Furthermore, the primary types involve H3K18Ac histone modification, while secondary and relapsing types of GBM have an H4K20triMe modification.

The distinction between primary and secondary GBMs allows for treatment of this disease as a progressive biological process. A breakthrough in this respect was the distinction of the classic, pro-neural, neural and mesenchymal subtypes of GBM due to the application of integrated genome analysis (12). The classic type involves amplification of 7 chromosomes and loss of 10 chromosomes, epidermal growth factor receptor gene mutation accompanied by quadruplicated expression, CDKN2A mutation or aberration of RB-pathway components (including RB1, CDK4 and CCDN2), no mutation of TP53, enrichment of Notch-pathway (NOTCH3, JAG1 and LFNG) and SHH-pathway genes (SMO, GAS1 and GLI2) (12). The pro-neural type of GBM is characterized by IDH1 mutations, and a high expression level of platelet-derived growth factor receptor (PDGFR) A and OLIG2, in addition to high expression level of the genes SOX, DCX, DLL3, ASCL1 and TCF4 families. Furthermore, markers of the neural type of GBM include NEFL, GABRA1, SYT1 and SLC12A5. Finally, the indicators of mesenchymal GBM include a low level of NF1 expression, PTEN mutation, appearance of YKL40 and MET markers; high level of CD44 and MERTK proteins and tumor necrosis factor and nuclear factor- $\kappa \mathrm{B}$-pathway protein expression also indicate the neural type of GBM. The mesenchymal subtype of GBM is particularly aggressive and radiation-resistant.

While oncogenetic research sheds light on specific aspects of carcinogenesis, it does not help to identify key targets for effective suppression of GBM proliferation and invasive growth, to overcome radiation and chemotherapy resistance, or to determine why there is a quick relapse of glioblastoma subsequent to surgery. Significant immunohistochemical differences in the cellular composition of primary GBM and following relapse remain to be understood. These properties of glioblastoma are considered to be associated with CSCs.

Advances in experimental medicine and cytometric technologies have advanced our interpretation of CSCs within the context of existing views on the nature of neoplastic processes. CSCs have been reported to trigger tumor growth even when small numbers are implanted into the animal brain $(14,15)$. The production of specific ATP-binding cassette transporters (ABCG2 and ABCA3), whose function is to eliminate chemical substances within the cells, renders them non-responsive to chemotherapy. The ability to restore damaged DNA is provided by the CSC production of MGMT factor which, in combination with ATM, Rad17, Chk2 and Chk1 activation, helps a cell with an irradiation-damaged genome to progress through the crucial stages of the cell cycle and to proliferate.

The cellular heterogeneity of CSCs explains, in part, the cellular heterogeneity of GBM. The immunocytochemical properties of CSCs include clusters of cellular surface

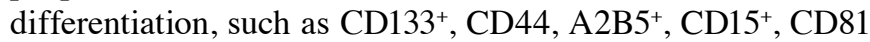
and TPT1 among others (16). The differences of these cells are disputable, and there is variability in their ability to induce tumor growth in animals. Furthermore, they have different responses to radiation and chemotherapy. Apart from CSCs $(6,7)$, glioblastoma tissue includes cancer stem progenitor cells, tumor-inducing cells and other specific 
types of cells (16). Reversible transitions between different phenotypes of cells are possible, as well.

CSCs expressing CD133 ${ }^{+}$display non-adhesive formation of neurospheres (gliomaspheres) in vitro and are capable of limited non-invasive growth in vivo, while they are sensitive to radiation. $\mathrm{CD} 44^{+} \mathrm{CSC}$ adhere to substrates in vitro, rapidly trigger invasive growth and are radiation-resistant. In addition, $\mathrm{CSCs}$ that are $\mathrm{CD} 133^{+} / \mathrm{CD} 44^{+}$are able to rapidly create gliomaspheres, exhibit a high index of invasion in vitro, trigger rapid infiltration processes in vitro, and are resistant to radiation and relatively sensitive to temozolomide (17). There is also a cluster of CSCs characterized by the expression of immature nervous and embryonal tissue markers, including nestin, SOX2, SALL4, OCT4, STAT3, NANOG and c-Myc (18). These latter cells are considered to have significantly more differential freedom compared with either $\mathrm{CD} 133^{+}$or $\mathrm{CD} 44^{+}$cells (13).

In view of the aforementioned findings, a personalized oncologic treatment is impossible without the application of flow cytometry and cellular sorting, although further steps are also required. It is likely that $\mathrm{CD} 133^{+} \mathrm{CSC}$ are associated with the pro-neural type of GBM, while CSCs expressing CD44+ are characteristic of the mesenchymal type $(12,13)$; nevertheless, such a division is rather provisional. GBM has several active zones of cellular division where the cellular phenotype of CSC descendants depends on the intensity and length of hypoxic preconditioning/cytokine activity, activity of secretome factors and recruited non-cancer cells (microglia and fibroblasts), as well as radiation and anti-tumor chemotherapy. Thus, the main vector of CSC clonal selection that influences the basic properties of these cells is crucial to understanding the glioblastoma biology.

CSCs are quick to produce generations of progenitors from which only clones with the strongest adaptability to the existing microconditions can survive, thereby defining the molecular phenotype of cells in a relapsing tumor. For this reason, emphasis in developing a treatment program should focus on molecular targets (ligand-receptor complexes) identified from proteome analysis of the main subtype (or subtypes) of CSCs extracted from the patient's tumor. Proteome characteristics of CSCs demonstrate the actual condition of GBM hierarchy, while properties of cancer cells in the common pool are less important.

GBM cells have a specific and well-organized system of intercellular communication. According to electron microscopy data, U87 human glioblastoma cells actively interact with each other by complete or partial fusion (Fig. 1A-C), create strong contacts among cells with interdigitation and subsequent dissolution of the cytomembrane (Fig. 1D-F), with formation of special cytomembrane differentiations in the form of tubes and connecting bridges (Fig. 1G-I). Exchange of intracellular contents (and information) is a crucial part of these contacts. This communication network is credited for the fast GBM relapse following surgical removal $(19,20)$, as well as for the resistance of this tumor to medication and radiation $(21,22)$, the development of hierarchy (17), and the creation of CSC niches (23). GBM cells freely exchange fluorescent markers, which become directly connected to cellular proteins while staining (24), indicating the cytoplasmic transfer between neoplastic cells of different immunohistochemical phenotypes (Fig. 2)
Cancer cells are informationally accessible living systems with a dynamic proteome and unique abilities for intercellular collaboration (25). Dynamic changes of the proteome of GBM cells during intercellular interaction are likely to be a key regulator of oncogenes and onco-suppressor activity that stimulates the creation of highly invasive GBM cell clones. Since CSCs occupy a central position in the hierarchy of glioblastoma cells, the CSC proteome is a key target for regulation of all cancer cell activity. Epithelial-mesenchymal transition (EMT) is a strategically important mechanism of modifying the cancer cell proteome (25).

EMT is a complex morphogenetic program whereby epithelial cells lose their apical-basal polarity, break intercellular contacts, undergo cytoskeletal reorganization, secrete extracellular matrix proteins and are transformed into mobile mesenchymal cells (26). Glioblastoma cells with EMT display marked alterations in their proteome (27). This mechanism is likely to control the transition of GBM from the pro-neural type to the more aggressive mesenchymal type. EMT is also an important mechanism of generating new CSC types (28) and reinforcing their invasive properties (29).

Hypoxia is a main driver of EMT and a strategic factor of GBM biology. The ability of hypoxia to induce the EMT has been proven in models of breast cancer (29), renal carcinoma (30), stomach cancer (31), colon cancer (32), pancreatic cancer (33) and other epithelial tumors (34). Glycolysis is a priority type of metabolism in tumor cells. Different types of GBM cells can be either glycolytic or use oxidative phosphorylation. It is considered that, the more aggressive the CSC clone, the more glycolytic it is; however, CSCs are able to switch between the two types of energy metabolism depending on external conditions (35). Alteration of the metabolic profile of CSCs is possible under the influence of factors induced by hypoxia. Hypoxia-inducible factors (HIFs) activate metabolic genes (such as GLUT1 and GLUT3), trigger alternative pathways for glucose utilization (including the polyol and pentose phosphate pathways) and interact with the components of the Wnt, NF- $\kappa \mathrm{B}$, transforming growth factor $\beta$ (TGF- $\beta$ ) and PI3K/AKT/mTOR signaling pathways. In addition, HIFs stabilize cell energy, prevent apoptosis and ensure the survival of tumor cells. Therefore, a high level of HIF expression in GBM tissue is one of the key conditions for the generation of new CSCs (35).

In GBM tissue, hypoxia induces the expression of $>80$ cytokines, and among these is TGF- $\beta$. TGF- $\beta$ is a member of a large cytokine family that participates in the regulation of embryonal development and tissue homeostasis. This factor acts through a complex signaling network of ligands and receptors. In cancer, TGF- $\beta$ signaling has both suppressing and stimulating functions (36), known as the TGF- $\beta$ paradox. TGF- $\beta 1$ stimulation markedly alters the molecular phenotype of GBM cells (29), increasing the production of 512 proteins associated with the change of molecular phenotype to a mesenchymal one. TGF- $\beta$ promotes the transmission of signals through RHO-like GTPases, PI3K and mitogen-activated protein kinase (MAPK) pathways that also stimulate EMT. In GBM, hypoxia is a destructive factor for pathogenesis (37), triggering EMT and reinforcing the stem properties of cancer cells (38).

Taking the aforementioned observations into account, the most effective strategy for improving the median survival of 

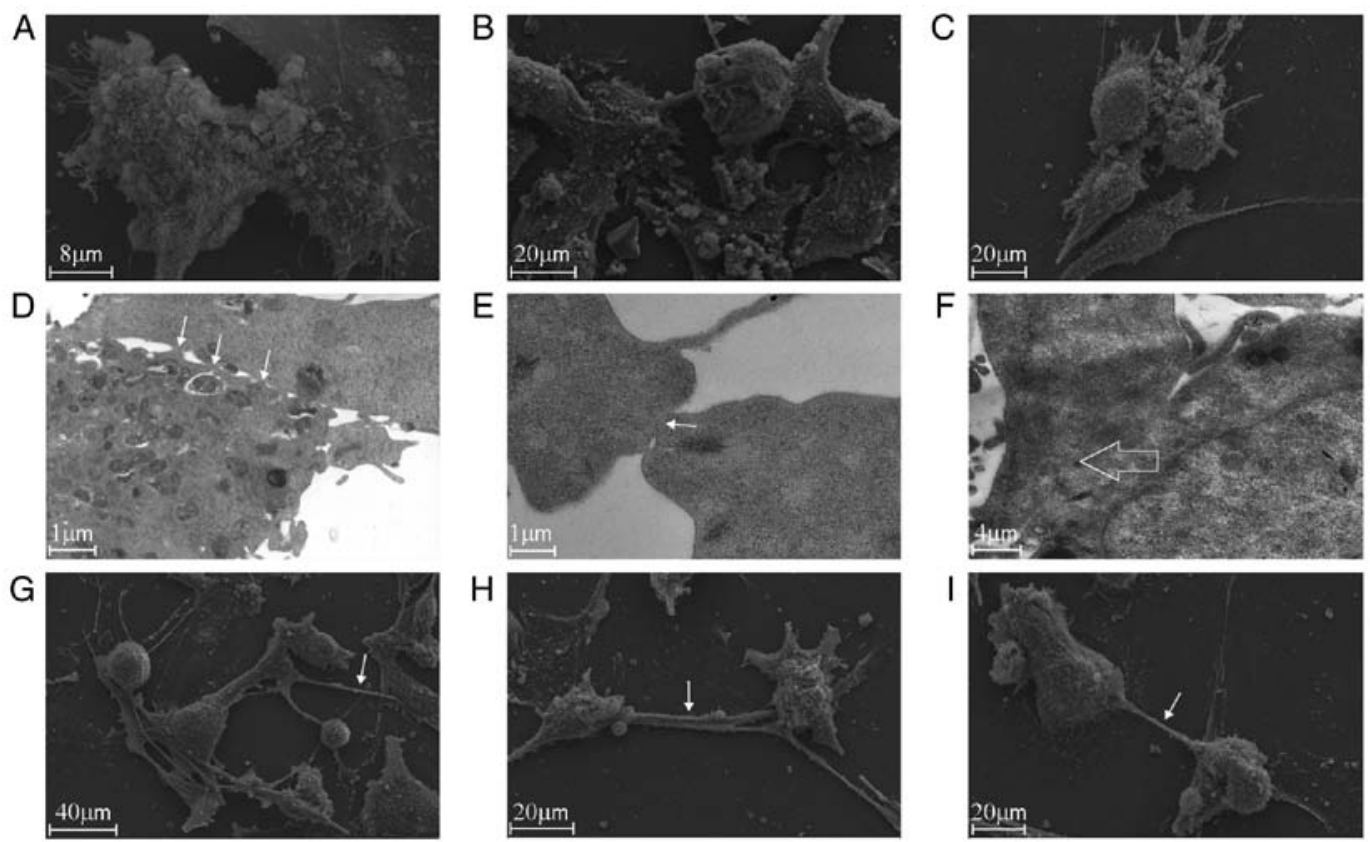

Figure 1. Electron microscopy examination of human glioblastoma U87MG cells, indicating the mechanisms of glioblastoma cell interaction, examined by the authors. (A) Fusion of two interacting cells (magnification, x2,300). (B) Numerous mergers between cells (magnification, $\mathrm{x} 953$ ). (C) Conglomerate forming from interacting cells (magnification, x793). (D) Creation of close contacts among the cells with interdigitations (magnification, x13,380). (E) formation of gap junctions (magnification, $\mathrm{x} 40,150$ ). (F) subsequent dissolution of cytomembrane (magnification, $\mathrm{x} 28,600$ ); (G) Special differentiation of cytomembrane into microtubes and/or connective bridges (magnification, x493). (H) Formation of microtubes between remote cells (magnification, x919). (I) Microtubes formation between close cells (magnification, x798).

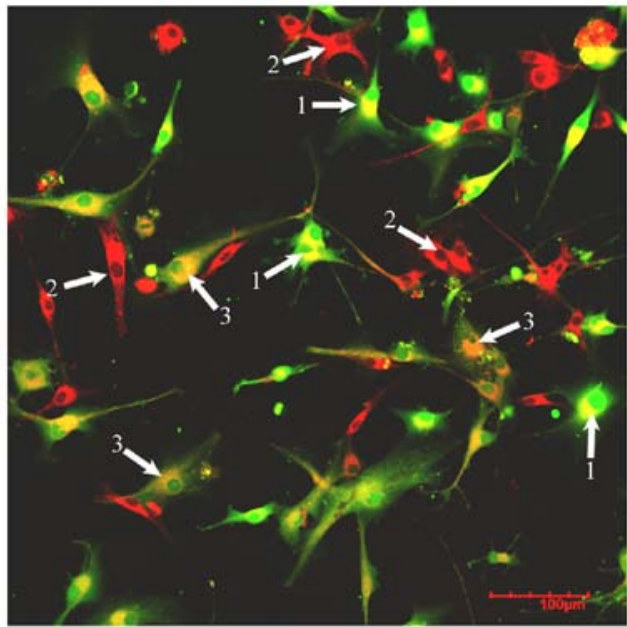

Figure 2. Fluorescent laser microscopy examination of glioblastoma U87MG cell culture, examined by the authors. Green tag (arrows labeled 1) represents CD133 ${ }^{+}$cells stained with Vybrant ${ }^{\circledR}$ CFDA SE cell tracer (V12883; Molecular Probes; Thermo Fisher Scientific, Inc., Waltham, MA, USA; $\lambda=488 \mathrm{~nm} ; 25 \mu \mathrm{M}$ in PBS for $25 \mathrm{~min}$ at $37^{\circ} \mathrm{C}$ ). Red tag (arrows labeled 2) represents CD $44^{+}$cells stained with CellTracker ${ }^{\mathrm{TM}}$ Red CMTPX Dye (C34552; Molecular Probes; Thermo Fisher Scientific, Inc.; $\lambda=546 \mathrm{~nm}$ $15 \mu \mathrm{M}$ in DMEM for $25 \mathrm{~min}$ at $37^{\circ} \mathrm{C}$ ). Staining was conducted according to the manufacturer's protocol. After $48 \mathrm{~h}, \mathrm{CD} 133^{+}$showed red fluorescent tag indicating the presence of cytoplasm components, $\mathrm{CD} 44^{+}$cells (arrows labeled 3).

GBM patients involves putting more effort into destroying key targets in the primary type of CSCs and suppressing the mechanisms of CSC proteome destabilization. These tasks are achievable through the use of post-genome biomedical technologies in GBM therapy.

\section{Complex therapy of glioblastoma and CSC protein targets}

In GBM, surgery does not guarantee complete elimination of cancer cells; thus, the main focus of treatment is radiation therapy (39). The standard procedure involves 25-30 radiation fractions for 5-6 weeks five times a week, with a dosage of 1.8-2.0 Gy. The patient's life expectancy correlates with the total radiation dose $(40)$, reaching $60-70$ Gy $(1,2)$. Suggested GBM relapse prevention methods include brain irradiation with a dose of up to $50 \mathrm{~Gy}$ per year. The combination of surgery and radiation in the CyberKnife system appears to be promising as a method of delivering radiotherapy, with the intention of treatment targeted more accurately than standard radiotherapy (41). In addition, brachytherapy involving radioactive isotopes of iodine, gold and iridium allows for application of a large dose of radiation directly to the tumor. Radiation treatment applied with a linear accelerator can also be potentially successful (42). Nevertheless, radiation is one of the strongest EMT-inducing factors that reinforces the invasive properties of CSCs $(42,43)$. In turn, a combination of surgery and radiation intensifies hypoxia and triggers canonic signaling pathways of eukaryotic cell survival (44), accompanied by cell rounding, autophagy (45), cell dedifferentiation and expression of embryonic cell surface markers (such as STAT3, Nanog and Okt4), thus enriching the CSC population (38) and significantly increasing its heterogeneity

There are no effective means of suppressing dedifferentiation and EMT, although the possibility of combining radiation treatment and hyperbaric oxygen therapy has been discussed (46). While potentially useful, the Warburg effect in cancer cells is determined by mutations and, as such, 
controlling external hypoxia does not decrease the pace of lactate synthesis that, together with oxidative stress, is a powerful inducer of EMT in cancer cells (47).

The main emphasis is currently placed on chemotherapy that can prolong the non-relapse period. The gold standard is temozolomide, which is recommended for primary and metastatic brain tumors (39). Its cytotoxic effect is due to the disruption of the structure and synthesis of DNA. The PCV (involving the use of procarbazine, lomustine and vincristine) and CAP (involving cyclophosphamide, doxorubicin and cisplatin) schemes are less popular. Carmustine, nimustine, fotemustine, dacarbazine, irinotecan, etoposide, cisplatin, carboplatin and paclitaxel also have limited use. The disadvantage of the abovementioned agents lies in their inability to destroy CSCs.

Low effectiveness of chemotherapy can be attributed to the insufficient use of new technologies. According to our previous data (10), among the entire spectrum of signaling pathways with a domain in CSC membranes, CD133 ${ }^{+}$glioblastoma stem cells of the U87 cell line have only 10 signaling pathways with intact signaling clusters in the cytoplasm and nucleus. Special attention should be directed to the angiogenesis signaling pathway, Rho GTPase, epidermal growth factor (EGF), fibroblast growth factor, chemokine-mediated pathway of inflammation, integrin pathway, focal adhesion, MAPK and Wnt signaling pathways.

One of the suggested approaches to destabilize the CSC energy metabolism is the application of indinavir, ritonavir, nigericin, metformin and ivermectin in combination with a ketogenic diet. Key enzymes targeting the bioenergetic CSC pathways, such as lactate dehydrogenase, pyruvate kinase muscle isozyme 2 (48), aldehyde dehydrogenase (49), isocitrate dehydrogenase (50), enzymes of glucose-transporter systems (including GLUT1, 2, 3, 6, 8 and 13) (51), hexokinase 2 (52), aldolase A, pyruvate dehydrogenase kinase 1 , 6-phosphofructo-2-kinase/fructose-2,6-bisphosphatase 4 (53) have been widely studied. A promising target for the suppression of aerobic respiration processes in CSCs is the insulin-like growth factor 2 mRNA-binding protein (35). However, this therapy is not sufficiently effective.

Concentration on these targets helps to impede certain key functions of CSCs. It is possible to target Rho GTPase (54), signaling pathways of MAPK (Sunitinib), EGF (cyclopamine, gefitinib, erlotinib and lapatinib), and PDGF (imatinib and tandutinib). Targeting proteins of CSC telomeres, such as TRF1 (55), is also possible. However, these therapies exhibit certain disadvantages. For instance, bevacizumab, which is an inhibitor of the biological activity of vascular endothelial growth factor (VEGF) and is widely used in GBM treatment, stimulates EMT $(56,57)$. This drawback is typical for tyrosine kinase inhibitors targeting tumor angiogenesis. Standard combination GBM therapy leads to intensive accumulation of new CSC clones in the tumor, thus creating a vicious circle causing relapse and patient mortality.

One potential way to solve this problem is total suppression of all CSC-type pluripotency by targeting a key mechanism regulating cellular proliferation and differentiation during prenatal development, namely, the Wnt signaling pathway. The latter is inactive in adult organisms, with the exception of normal stem cells (58) where it serves an important role in supporting pluripotency. In different types of cancer $(59,60)$ activation of the Wnt/Frizzled signaling pathway promotes CSC proliferation and induces EMT. Therefore, targeting this factor may limit the reproductive and invasive properties of CSCs (61).

Excessive activation of the Wnt signaling pathway in GBM cells is achieved through epigenetic changes that inhibit the expression of antagonist proteins (such as NKD1-1, sRFP1-5 and DKK1/3) and/or cause massive overexpression of active pathway components (including Wnt6, FZD2, FZD9 and Dvl2) (62). Such activation of the Wnt cascade renders GBM similar to the most aggressive triple-negative subtype of breast cancer (63).

While little is known about the use of Wnt pathway inhibitors for GBM treatment, a number of examples are described as follows: Clofazimine, a drug used to treat leprosy and specific types of tuberculosis, appears to also be an efficacious inhibitor of Wnt signaling in Wnt-dependent types of breast cancer (64). Aspirin suppresses Wnt-signaling in colorectal cancer cells (65-67), while non-steroidal anti-inflammatory drugs (such as diclofenac and celecoxib) suppress this signaling pathway in GBM cells (68). In turn, celecoxib is capable of suppressing the activity of MRP1-5, ABCA2 and ABCG2 transporters that export drugs from cancer cells (69). In addition, regorafenib reduces the activity and lowers the expression of Wnt pathway genes (70). A similar effect is produced by the antibiotics nigericin and monensin that impede the progression of intestinal cancer (71). It has also been reported that inhibition of the Wnt pathway by the polyether antibiotic salinomycin prevents GBM cell transformation into cancer stem-like cells (72). Niclosamide, which has anthelmintic properties, significantly reduces the number of pluripotent cells and diminishes their invasive potential by suppressing several signaling pathways, such as WNT/ $\beta$-catenin, NOTCH, mTOR and NF- $\mathrm{B}(73,74)$. Niclosamide also inhibits the $\mathrm{WNT} / \beta$-catenin pathway in colon, ovary, breast and prostate cancer, and in osteosarcomas (75-80). Furthermore, silibinin, a flavonolignan antioxidant, suppresses the Wnt cascade in stem cells of breast and prostate cancer (81), as well as in lung cancer (82).

Collectively, radiation and anti-angiogenic therapy transform the CSC proteome and trigger EMT. In principle, proteome mapping of CSCs allows to increase the effect of chemotherapy due to application of tyrosine kinase inhibitors. Introduction of Wnt pathway antagonists into treatment protocols will limit the reproductive capacity of neoplastic cells. However, prolonged remission is impossible without regulating the mechanisms of CSC molecular phenotype generation and transformation. Targeting these mechanisms is possible via a therapeutic approach based on normal human stem cells.

\section{Biomedical cellular technologies in glioblastoma therapy}

Mammalian and human postnatal stem cells possess pronounced anti-tumor potential, while they are capable of directed migration to and interaction with tumor cells. Previous studies by our group $(83,84)$ and studies by other researchers $(85,86)$ have described this phenomenon using models of gliomas, metastatic melanoma (87), solid tumors (88) and CSCs of metastatic tumors (89). The vector of migration 
activity for normal tissue-specific stem cells in relation to GBM cells is inversely proportional to the differentiation level of cancer cells and is more pronounced among cells with one histogenetic source in the brain (86) that allows to target CSCs directly using neural stem cells.

A strong similarity between the proteomes of glioblastoma CSCs and human normal neural stem cells $(10,84)$ indicates their involvement in carcinogenesis. Normal bone marrow stem cells lack this disadvantage, since they are very mobile compared with cancer cells that adhere to their surface and interact with them. An important stage of this contact is likely to be the transfer of proteome and/or secretome components, as illustrated in Fig. 3A-D. This phenomenon is observed in $40 \%$ of C6 glioma cells, 77\% of lung cancer cells (A549), $47 \%$ of breast adenocarcinoma cells and $64 \%$ of human glioblastoma cells $(83,84)$.

Interaction between stem cells and cancer cells may involve gap junctions between normal bone marrow stem cells and low-grade differentiation glioma cells. Such junctions allow the exchange of micro-RNA, and trigger p53-induced apoptosis that is likely to be a mechanism of the anti-tumor potential of stem cells (90). Gap junctions can allow the transport of relatively small molecules, while excluding the transmission of cytoplasm proteins. Gap junctions are likely to co-exist with other mechanisms of intercellular interaction, for instance, with the creation of close syncytial contacts with subsequent complete or partial cell fusion. GBM cells have a high fusion potential (91-93). Cultivation of glioma and carcinoma cells $(83,84)$ with hematopoietic stem cells (HSCs) and fibroblasts (91) results in a higher number of fusions and creation of cells with two fluorescent tags. This cell fusion promotes the formation of tumorigenic hybrid cells (92) and enhances tumor heterogeneity (93). This mechanism also permits epigenetic re-programming of cancer cells by means of HSC cytoplasm factors.

Another mechanism of intercellular interaction involves the production of microvesicles by HSCs. Stem cells of all types secrete microvesicles transporting RNA and/or DNA that modify the local microenvironment. Microvesicles may, thus, be considered as a strategic component of CSC epigenetic regulation. The effect of microvesicles is directly associated with their content that is significantly determined by the specifics of their paracrine function. The ability to produce VEGF is part of the HSC restoring program (94). Inhibition of VEGF/VEGF-R signaling (95) stimulates tumor growth and triggers EMT (49), while production of VEGF by stem cells suppresses EMT (96). VEGF activates CSCs in the hypoxic niche and facilitates their differentiation into blood vessel endothelial cells, preventing their transformation into highly aggressive CSCs $(97,98)$.

Reprogramming CSCs via transcriptomic factors of the HSC proteome and transcriptome provides possibilities for EMT suppression. Interaction with HSCs strongly inhibits the activity of glial tumors; this phenomenon is dose-dependent and, to a certain extent, explains stem cell migration to the tumor. Modified content of interacting cellular systems or previous affection of HSCs results in the development of specific interrelated effects inside the cellular population and is accompanied by regular modulations in their microenvironment. Pretreatment of HSCs with non-lethal doses of cytostatics increases their anti-tumor potential (99). Interaction between bone marrow stem cells modifies their proteome and secretome, and GBM cells with EMT phenotype display decreased cell mobility, destabilized CSC links with extracellular matrix and diminished invasion. As shown in Fig. 4, this mechanism was explored using a culture model of C6 glioma and HSC cells treated with fascaplysin, a potent alkaloid CDK-4 inhibitor (99), and the results suggested clinical potential.

Mesenchymal stem cells (MSCs), well-known for their anti-tumor properties, represent a promising instrument for CSCs as MSCs can suppress their invasion and proliferation. Chemotherapy and transplantation of MSCs have been reported to improve the survival rate in animals with glioma $(100,101)$. In homotransplantation, these cells escape rejection, which makes possible the use of homogeneous material from public stem cell cryobanks to create new anti-tumor biomedical cellular products (102).

The highest hopes for developing new strategies in oncology and regenerative medicine lie with the MSC secretome (103). MSC-derived microvesicles can be used in monotherapy, as well as together with other components of cell-based products. MSC-derived exosomes are stable in the extracellular medium, safe for patients and absorbed by cancer cells, while they suppress the growth of glial tumors (104).

The high content of angiogenetic factors in exosomes renders them an effective treatment instrument (105). The anti-tumor properties of MSC exosomes depend on their origin (106) MSC-derived exosomes from the menstrual endometrium block prostate tumor-induced angiogenesis (107), inhibit the activity of NF- $\kappa \mathrm{B}, \mathrm{VEGF}, \mathrm{HIF}-1 \alpha$ and PDGF/PDGFR. Furthermore, MSC-derived exosomes of bone marrow (108) stimulate the interphase in breast cancer metastatic cells, while MSC-derived exosomes from adipose tissue induce the apoptosis of ovarian cancer cells (109).

The anti-tumor properties of exosomes are associated with the transportation of BAX, CASP9 and CASP3 proteins (110), and microRNA families, such as let-7a, miR-34, miR-31, miR-451, miR-145, miR-200/141, miR-14/15, miR-23b, miR-223 and miR-224 (111). It has been reported that miR-124 inhibits EMT in glioma cells (112), and miR-145-5p impedes EMT in esophageal carcinoma (113). In addition, the miR-200a family suppresses EMT in renal cancer cells (114), and miR-23b inhibits EMT in ovarian cancer cells (115). miR-451 stops EMT in neuroblastoma cells (116), bladder cancer cells (117) and osteosarcoma (118). Furthermore, miR-34 inhibits pancreatic CSC activity (119), while miR-181 and miR-21 (120) impede $\mathrm{NF}-\kappa \mathrm{B}$ signaling that prevents the expression of Toll-like receptors in glioblastoma stem cells, thus decreasing their stem properties. miR-92a from MSC-derived exosomes stops angiogenesis (104), while miR-145 inhibits the proliferation, migration and invasion of neoplastic cells $(121,122)$. Finally, miR-146b significantly suppresses glioma growth (123). The aforementioned observations identify a molecular arsenal of exosomes that control EMT in GBM cells.

Another mechanism of CSC activity suppression is modulation of the monocyte-macrophage system by combining MSC-derived exosomes with mononuclear CD $45^{+}$cells from human blood $(124,125)$. Injection of haploidentical rat $\mathrm{CD} 45^{+}$ cells into rats with brain glioma led to a rapid increase in tumor cell numbers with microglial markers. These markers 
A

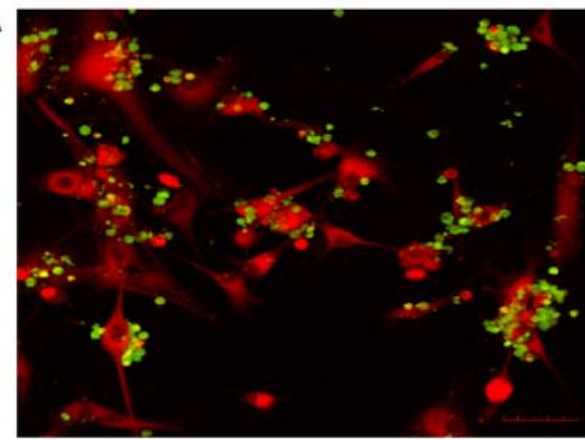

C

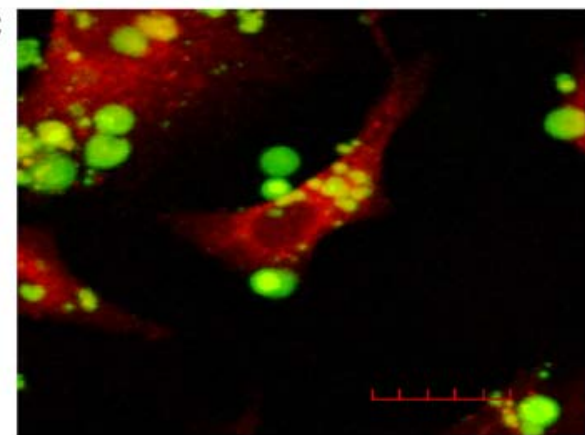

B

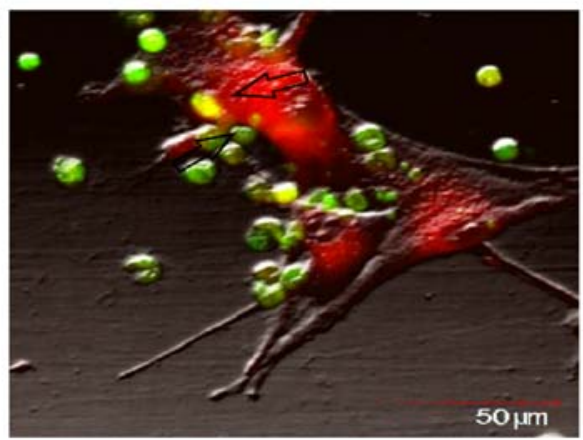

D

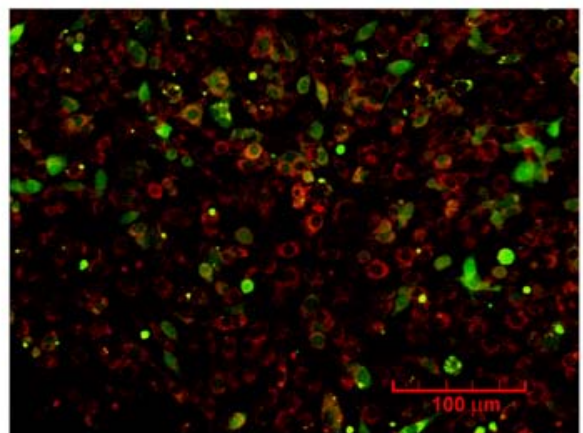

Figure 3. Fluorescent laser microscopy examination of combined culture of stem and cancer cells of human glioblastoma, examined by the authors. Green tag represents hematopoietic stem cells stained with Vybrant ${ }^{\circledR}$ CFDA SE tracer (V12883; Molecular Probes; Thermo Fisher Scientific, Inc.; $\lambda=488$ nm; $25 \mu$ M in PBS for $25 \mathrm{~min}$ at $37^{\circ} \mathrm{C}$ ). Red tag represents glioblastoma cells stained with CellTracker ${ }^{\mathrm{TM}}$ Red CMTPX Dye (C34552; Molecular Probes; Thermo Fisher Scientific, Inc.; $\lambda=546 \mathrm{~nm} ; 15 \mu \mathrm{M}$ in DMEM for $25 \mathrm{~min}$ at $37^{\circ} \mathrm{C}$ ). (A) Adhesion of HSCs to cancer cells; (B) fluorescent tag exchange; components of fluorescent $\operatorname{tag}(\mathrm{C})$ on the surface and (D) in the cytoplasm of cancer cells.

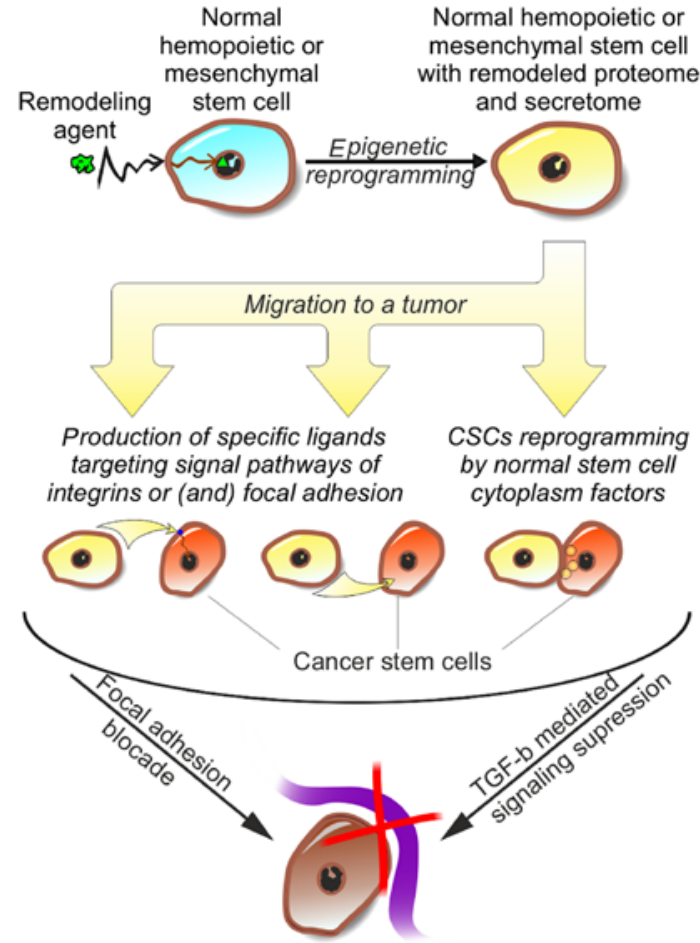

Figure 4. Scheme of personalized therapy for glioblastoma multiforme involving hematopoietic stem cells with remodeled proteome and secretome. Cellular therapy results in breaking the connection between CSCs and extracellular matrix, impeding invasion. CSCs, cancer stem cells; TGF- $\beta$, transforming growth factor $\beta$.

are frequently attributed to tumor progression (126). However, morphochemical modification of the glioma node as a response to injection of mononuclear cells does not always increase life expectancy of these rats. The decisive factors are the localization and qualitative parameters of microglia.

Bone marrow cell accumulation in the tumor is largely due to the formation of neoplastic blood vessels as a direct response to intracellular hypoxia (127). Only a small number of HSCs are capable of penetrating the intact blood-brain barrier. The brain is normally protected by resident microglia originating from the embryonic yolk sack, which support their population by proliferating, while bone marrow cells are not involved in this process. The creation of blood vessels in GBM allows the recruitment of stem and progenitor cells, as well as other bone marrow cells, with their subsequent transformation into microglia. This may lead to the conclusion that tumor growth induced by these cells is partially determined by hypoxic preconditioning (127). Hypoxia stimulates alternative activation of macrophages (M2 state) that amplifies their phagocytic activity, while it increases the synthesis of interleukin (IL)-10, TGF- $\beta 1$ and other anti-inflammatory cytokines that promote remodeling of necrotized tissue (128), cell migration, disruption of epigenetic regulation of genes (129) and generation of new CSCs. Hypoxia is likely to activate a paracrine function of CSCs (130). Production of periostin (131) and other EMT moderators is mainly attributed to cells expressing M2 microglial markers in the CSC microenvironment. These cells create secretory loops, and together with fibroblasts, they actively produce TGF- $\beta$ and trigger generation of CSCs with an EMT phenotype.

Suppression of CSCs with the most invasive phenotype is possible in the case of classic macrophage activation (M1 state). M1 activation is reflected by robust production of reactive 


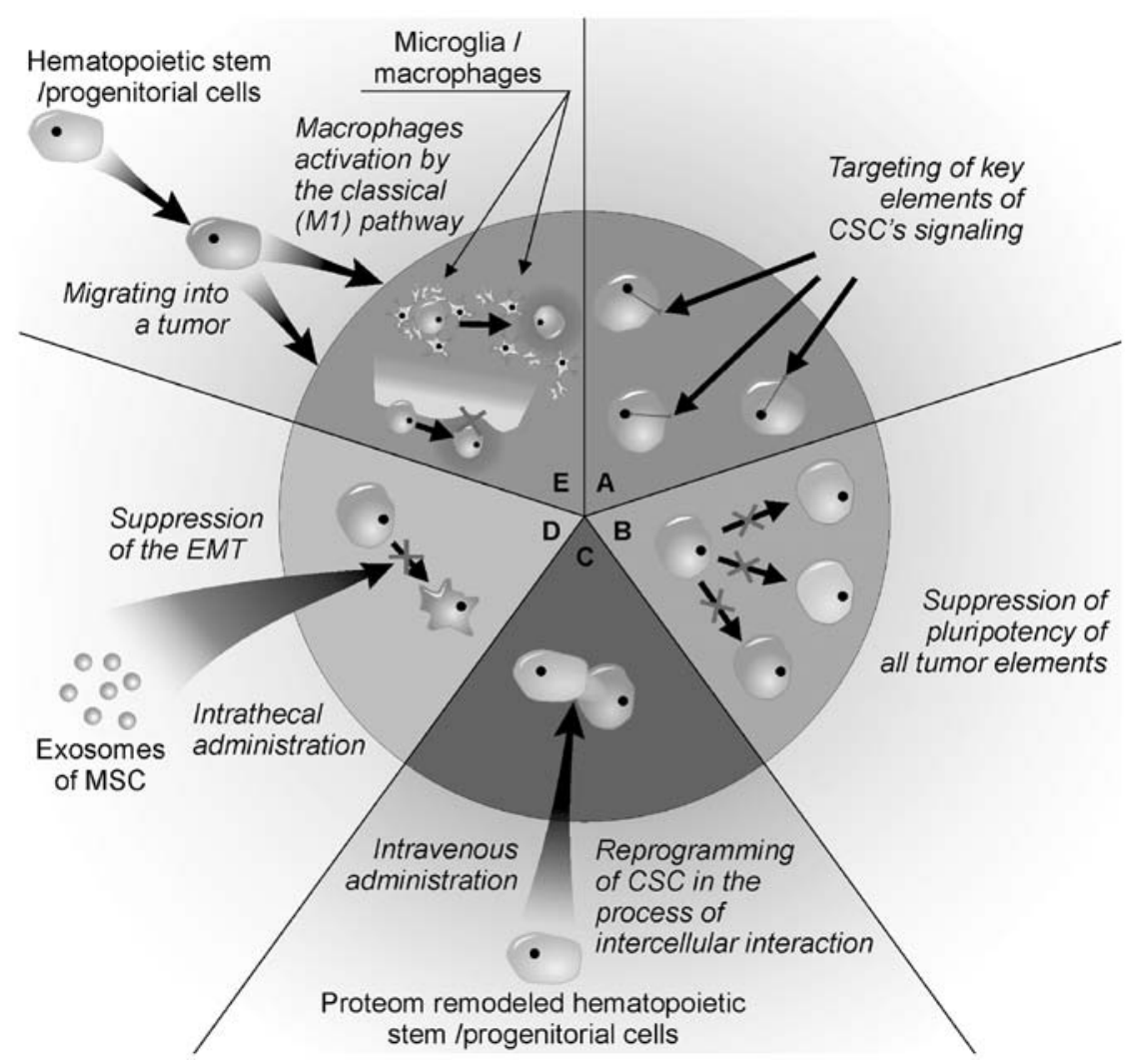

Figure 5. Methods of personalized regulation of glioblastoma cancer stem cells. (A) Identification of molecular targets in CSC proteome and their inhibition with chemotherapeutic agents. (B) Suppression of pluripotency in all types of CSCs via using inhibitors of Wnt-dependent signaling pathway. (C) Reprogramming of CSCs during their interaction with normal stem cells. (D) Inhibition of EMT in CSCs using exosomes of MSCs. (E) Destabilization of CSC interaction with local microsurroundings and extracellular matrix via monocytes and macrophages with a set vector of classic (pro-inflammatory) pathway activation. CSC, cancer stem cell; EMT, epithelial-mesenchymal transition; MSC, mesenchymal stem cell.

oxygen and nitrogen oxide species, TNF- $\alpha$, IL-1, IL-6, IL-12 and other inflammatory cytokines that promote inflammation, damage the extracellular matrix and prevent cancer cells with EMT from adhesion. Standard activators of the M1 state are bacterial lipopolysaccharides, interferon- $\gamma$, TNF- $\alpha$ and IL- $1 \beta$, IL-12, IL-18 and IL-23. The introduction of mononuclear cells with MSC-derived exosomes affected by systemic inflammatory response triggered by bacterial lipopolysaccharide can result in stronger local inflammation, destruction of the extracellular matrix, and disruption of the communication between CSCs and their microenvironment. In principle, microglia are capable of impeding self-regeneration (120) and even destroying CSCs. This is probably possible with the use of other modern methods of antitumor immunotherapy (132), although this requires further study.

\section{Conclusion}

The success of medicine depends on the efficiency of its methods. While traditional surgery does not solve the problem of GBM treatment, more radical surgery that incorporates modern scientific advances is an indispensable part of the therapy. Surgery eliminates a significant number of cancer cells, including CSCs that promote the proliferation of adjacent cells, thus rendering tumors responsive to treatment. However, further GBM therapy can be effective only with personalized regulation of CSCs based on post-genome and biomedical cellular technologies (Fig. 5).
Extraction of primary GBM cells, their immunohistochemical description, determination of the dominating types of CSCs, and proteome mapping and bioinformatics analysis are the most important stages in developing an effective treatment program. The CSC proteome reflects the state of the tumor system at a certain moment. Emphasis should be placed on cell surface molecular targets of the main CSC type that are associated with intact intracellular signal transduction pathways and able to impede key CSC functions (Fig. 5A). The main focus should be on the inhibition of tyrosine kinases (such as PDGFR, fibroblast growth factor, EGF and HIF) and targeted therapy.

A CSC is an informationally accessible system with a dynamic proteome and unique abilities of intercellular communication. For this reason, it is preferable to focus on regulating the predominant type of CSCs and attempting to suppress pluripotency of all GBM stem cells. Introduction of Wnt-signaling inhibitors into complex treatment protocols is considered to be the most reasonable step, emphasizing on combinations of established medications (Fig. 5B). In the absence of contraindications, radiation therapy should be combined with hyperbaric oxygenation. Cytotoxic and cytostatic chemotherapies should only be used with knowledge of molecular determinants of the dominant CSC type's response to a given drug.

EMT suppression in CSCs is, in principle, a crucial step in treating invasive tumors. This goal can be achieved through biomedical drugs based on the MSC secretome and HSC agents (Fig. 5C and D). Destabilizing the 
interaction of CSCs with their local microenvironment and extracellular matrix is possible by modulating components of the cerebral macrophage-monocyte system during the systemic inflammatory reaction (Fig. 5E).

The information discussed in the present review allows to formulate the following key strategies of $\mathrm{CSC}$ regulation in the complex therapy of GBM: Cell-sorting technologies for determination of CSCs and personalization of treatment based on proteome and bioinformatics analyses; suppression of pluripotency in cancer cells of all types; and targeting EMT in GBM cells and destabilization of CSC interaction with local microenvironment and extracellular matrix by means of biomedical cellular products. While introduction of these principles is a goal for the near future, certain of these can even be implemented at the moment.

\section{Acknowledgements}

Not applicable.

\section{Funding}

The current study was funded by the Ministry of Education and Science of the Russian Federation (grant no. 14.584.21.0027; ID: RFMEFI58417X0030).

\section{Availability of data and materials}

The datasets used and/or analyzed during the current study are available from the corresponding author on reasonable request.

\section{Authors' contributions}

IB worked on the text of the article, proposed the idea of the study, developed the design and plan, offered methodological support, organized the scientific team and directed scientific guidance of the experimental part of the study. AP performed experiments on the interactions between HSCs and cancer cells in vitro. MK performed flow cytofluorometry. IL worked on the text of article as did YZ. SZ performed statistical analysis of the results. PM performed experiments on the stimulation of control cells with TGF- $\beta 1$. ME performed electron microscopy. VS conceived the proteom-based theory and YK designed the structure of the article, and offered methodological support. HS and AS counseled on issues related to CNS pathology and blood-brain barrier, and linguistic edits.

\section{Ethics approval and consent to participate}

The use of human samples for this study was approved by the Ethical Committee of the School of Biomedicine, The Far Eastern Federal University (Minute no. 1 of 02.02.2017) and the Academic Council of the School of Biomedicine. The consent was provided from the patients for their samples to be used for research.

\section{Consent for publication}

Not applicable.

\section{Competing interests}

The authors declare that they have no competing interests.

\section{References}

1. Stupp R, Toms SA and Kesari S: Treatment for patients with newly diagnosed glioblastoma-reply. JAMA 315: 2348-2349, 2016.

2. Omuro A and DeAngelis LM: Glioblastoma and other malignant gliomas: A clinical review. JAMA 310: 1842-1850, 2013.

3. Louis DN, Perry A, Reifenberger G, von Deimling A, Figarella-Branger D, Cavenee WK, Ohgaki H, Wiestler OD, Kleihues P and Ellison DW: The 2016 World Health Organization classification of tumors of the central nervous system: A summary. Acta Neuropathol 131: 803-820, 2016.

4. DeWitt JC, Mock A and Louis DN: The 2016 WHO classification of central nervous system tumors: What neurologists need to know. Curr Opin Neurol 30: 643-649, 2017.

5. Louis DN, Perry A, Burger P, Ellison DW, Reifenberger G, von Deimling A, Aldape K, Brat D, Collins VP, Eberhart C, et al: International society of Neuropathology-haarlem consensus guidelines for nervous system tumor classification and grading. Brain Pathol 24: 429-435, 2014.

6. Abou-Antoun TJ, Hale JS, Lathia JD and Dombrowski SM: Brain cancer stem cells in adults and children: Cell biology and therapeutic implications. Neurotherapeutics 14: 372-384, 2017.

7. Dirks PB: Cancer: Stem cells and brain tumours. Nature 444: 687-688, 2006

8. Baba E and Akashi K: The fundamental concept of cancer stem cell and the progress in cancer stem cell research. Nihon Rinsho 73: 721-725, 2015 (In Japanese).

9. Duesberg P, Mandrioli D, McCormack A and Nicholson JM: Is carcinogenesis a form of speciation? Cell Cycle 10: 2100-2114, 2011.

10. Bryukhovetskiy A, Shevchenko V, Kovalev S, Chekhonin V, Baklaushev V, Bryukhovetskiy I and Zhukova M: To the novel paradigm of proteome-based cell therapy of tumors: Through comparative proteome mapping of tumor stem cells and tissue-specific stem cells of humans. Cell Transplant 23 (Suppl 1): S151-S170, 2014.

11. Louis DN, Ohgaki H, Wiestler OD, Cavenee WK, Burger PC, Jouvet A, Scheithauer BW and Kleihues P: The 2007 WHO classification of tumours of the central nervous system. Acta Neuropathol 114: 97-109, 2007.

12. Verhaak RG, Hoadley KA, Purdom E, Wang V, Qi Y, Wilkerson MD, Miller CR, Ding L, Golub T, Mesirov JP, et al: Integrated genomic analysis identifies clinically relevant subtypes of glioblastoma characterized by abnormalities in PDGFRA, IDH1, EGFR, and NF1. Cancer Cell 17: 98-110, 2010.

13. Crespo I, Vital AL, Gonzalez-Tablas M, Patino Mdel C, Otero A, Lopes MC, de Oliveira C, Domingues P, Orfao A and Tabernero MD: Molecular and genomic alterations in glioblastoma multiforme. Am J Pathol 185: 1820-1833, 2015.

14. Thakkar JP, Dolecek TA, Horbinski C, Ostrom QT, Lightner DD, Barnholtz-Sloan JS and Villano JL: Epidemiologic and molecular prognostic review of glioblastoma. Cancer Epidemiol Biomarkers Prev 23: 1985-1996, 2014.

15. Rispoli R, Conti C, Celli P, Caroli E and Carletti S: Neural stem cells and glioblastoma. Neuroradiol J 27: 169-174, 2014.

16. Brown DV, Daniel PM, D'Abaco GM, Gogos A, Ng W, Morokoff AP and Mantamadiotis T: Coexpression analysis of CD133 and CD44 identifies proneural and mesenchymal subtypes of glioblastoma multiforme. Oncotarget 6: 6267-6280, 2015.

17. Bradshaw A, Wickremsekera A, Tan ST Peng L, Davis PF and Itinteang T: Cancer stem cell hierarchy in glioblastoma multiforme. Front Surg 3: 21, 2016.

18. Bradshaw A, Wickremesekera A, Brasch HD, Chibnall AM, Davis PF, Tan ST and Itinteang T: Cancer stem cells in glioblastoma multiforme. Front Surg 3: 48, 2016.

19. Osswald M, Jung E, Sahm F, Solecki G, Venkataramani V, Blaes J, Weil S, Horstmann H, Wiestler B, Syed M, et al: Brain tumour cells interconnect to a functional and resistant network. Nature 528: 93-98, 2015.

20. Weil S, Osswald M, Solecki G, Grosch J, Jung E, Lemke D, Ratliff M, Hänggi D, Wick W and Winkler F: Tumor microtubes convey resistance to surgical lesions and chemotherapy in gliomas. Neuro Oncol 19: 1316-1326, 2017. 
21. Sontheimer H: Brain cancer: Tumour cells on neighbourhood watch. Nature 528: 49-50, 2015.

22. Murphy SF, Varghese RT, Lamouille S, Guo S, Pridham KJ, Kanabur P, Osimani AM, Sharma S, Jourdan J, Rodgers CM, et al: Connexin 43 inhibition sensitizes chemoresistant glioblastoma cells to Temozolomide. Cancer Res 76: 139-149, 2016.

23. Hambardzumyan D and Bergers G: Glioblastoma: Defining tumor Niches. Trends Cancer 1: 252-265, 2015.

24. Milkina EV, Mischenko PV, Zaytsev SV, et al: Features of interaction between hematopoietic stem and tumor cells of different lines in vitro. Gens and Cells XI: 63-71, 2016 (In Russian).

25. Luo M, Brooks M and Wicha MS: Epithelial-mesenchymal plasticity of breast cancer stem cells: Implications for metastasis and therapeutic resistance. Curr Pharm Des 21: 1301-1310, 2015.

26. Chow KH, Park HJ, George J, Yamamoto K, Gallup AD Graber JH, Chen Y, Jiang W, Steindler DA, Neilson EG, et al S100A4 is a biomarker and regulator of glioma stem cells that is critical for mesenchymal transition in glioblastoma. Cancer Res 77: 5360-5373, 2017.

27. Bryukhovetskiy I and Shevchenko V: Molecular mechanisms of the effect of TGF- $\beta 1$ on U87 human glioblastoma cells. Oncol Lett 12: 1581-1590, 2016.

28. Li P, Zhou C, Xu L and Xiao H: Hypoxia enhances stemness of cancer stem cells in glioblastoma: An in vitro study. Int J Med Sci 10: 399-407, 2013.

29. Morel AP, Lièvre M, Thomas C, Hinkal G, Ansieau S and Puisieux A: Generation of breast cancer stem cells through epithelial-mesenchymal transition. PLoS One 3: e2888, 2008.

30. Zhang N, Hong B, Zhou C, Du X, Chen S, Deng X, Duoerkun S, Li Q, Yang Y and Gong K: Cobalt chloride-induced hypoxia induces epithelial-mesenchymal transition in renal carcinoma cell lines. Ann Clin Lab Sci 47: 40-46, 2017.

31. Yang SW, Zhang ZG, Hao YX, Zhao YL, Qian F, Shi Y, Li PA, Liu CY and Yu PW: HIF-1 $\alpha$ induces the epithelial-mesenchymal transition in gastric cancer stem cells through the Snail pathway. Oncotarget 8: 9535-9545, 2017.

32. Sun LL, Song Z, Li WZ and Tang SY: Hypoxia facilitates epithelial-mesenchymal transition-mediated rectal cancer progress. Genet Mol Res 15, 2016.

33. Li D, Qu C, Ning Z, Wang H, Zang K, Zhuang L, Chen L, Wang P and Meng Z: Radiation promotes epithelial-to-mesenchymal transition and invasion of pancreatic cancer cell by activating carcinoma-associated fibroblasts. Am J Cancer Res 6: 2192-2206, 2016.

34. Lehmann S, Te Boekhorst V, Odenthal J, Bianchi R, van Helvert S, Ikenberg K, Ilina O, Stoma S, Xandry J, Jiang L, et al: Hypoxia induces a HIF-1-dependent transition from collective-to-amoeboid dissemination in epithelial cancer cells. Curr Biol 27: 392-400, 2017.

35. Libby CJ, Tran AN, Scott SE, Griguer C and Hjelmeland AB: The pro-tumorigenic effects of metabolic alterations in glioblastoma including brain tumor initiating cells. Biochim Biophys Acta 1869: 175-188, 2018.

36. Massagué J: TGFbeta in cancer. Cell 134: 215-230, 2008.

37. Toyonaga T, Yamaguchi S, Hirata K, Kobayashi K, Manabe O, Watanabe S, Terasaka S, Kobayashi H, Hattori N, Shiga T, et al: Hypoxic glucose metabolism in glioblastoma as a potential prognostic factor. Eur J Nucl Med Mol Imaging 44: 611-619, 2017.

38. Bar EE, Lin A, Mahairaki V, Matsui W and Eberhart CG: Hypoxia increases the expression of stem-cell markers and promotes clonogenicity in glioblastoma neurospheres. Am J Pathol 177: 1491-1502, 2010.

39. Konovalov AN, Potapov AA, Loshakov VA, et al: Standards, options and recommendations in the treatment of CNS tumors. Assoc Neurosurg Russia, 2009 (In Russian).

40. Scott JG, Berglund A, Schell MJ, Mihaylov I, Fulp WJ, Yue B, Welsh E, Caudell JJ, Ahmed K, Strom TS, et al: A genome-based model for adjusting radiotherapy dose (GARD): A retrospective, cohort-based study. Lancet Oncol 18: 202-211, 2017.

41. Dincoglan F, Beyzadeoglu M, Sager O, Demiral S, Gamsiz H, Uysal B, Ebruli C, Akin M, Oysul K, Sirin S and Dirican B: Management of patients with recurrent glioblastoma using hypofractionated stereotactic radiotherapy. Tumori 101: 179-184, 2015.

42. Wang P, Lan C, Xiong S, Zhao X, Shan Y, Hu R, Wan W, Yu S, Liao B, Li G, et al: HIF1 $\alpha$ regulates single differentiated glioma cell dedifferentiation to stem-like cell phenotypes with high tumorigenic potential under hypoxia. Oncotarget 8: 28074-28092, 2017.
43. Colwell N, Larion M, Giles AJ, Seldomridge AN, Sizdahkhani S, Gilbert MR and Park DM: Hypoxia in the glioblastoma microenvironment: Shaping the phenotype of cancer stem-like cells. Neuro Oncol 19: 887-896, 2017.

44. Pecchia I, Dini V, Ricci-Vitiani L, Biffoni M, Balduzzi M, Fratini E, Belli M, Campa A, Esposito G, Cirrone G, et al: Glioblastoma stem cells: Radiobiological response to ionising radiations of different qualities. Radiat Prot Dosimetry 166: 374-378, 2015

45. Jawhari S, Ratinaud MH and Vernier M: Glioblastoma, hypoxia and autophagy: A survival-prone 'ménage-à-trois'. Cell Death Dis 7: e2434, 2016.

46. Stepień K, Ostrowski RP and Matyja E: Hyperbaric oxygen as an adjunctive therapy in treatment of malignancies, including brain tumours. Med Oncol 33: 101, 2016

47. Sridaran D, Ramamoorthi G, Mahaboob Khan R and Kumpati P: Oxystressed tumor microenvironment potentiates epithelial to mesenchymal transition and alters cellular bioenergetics towards cancer progression. Tumour Biol 37: 13307-13322, 2016.

48. Agnihotri S and Zadeh G: Metabolic reprogramming in glioblastoma: The influence of cancer metabolism on epigenetics and unanswered questions. Neuro Oncol 18: 160-172, 2016.

49. Choi SA, Lee JY, Phi JH, Wang KC, Park CK, Park SH and Kim SK: Identification of brain tumour initiating cells using the stem cell marker aldehyde dehydrogenase. Eur J Cancer 50: 137-149, 2014.

50. Clark O, Yen K and Mellinghoff IK: Molecular pathways: Isocitrate dehydrogenase mutations in cancer. Clin Cancer Res 22: 1837-1842, 2016.

51. Ojelabi OA, Lloyd KP, Simon AH, De Zutter JK and Carruthers A: WZB117 (2-Fluoro-6-( $m$-hydroxybenzoyloxy) Phenyl $m$-Hydroxybenzoate) inhibits GLUT1-mediated sugar transport by binding reversibly at the exofacial sugar binding site. J Biol Chem 291: 26762-26772, 2016.

52. Kathagen A,SchulteA,BalckeG,PhillipsHS,Martens T,MatschkeJ, Günther HS, Soriano R, Modrusan Z, Sandmann T, et al: Hypoxia and oxygenation induce a metabolic switch between pentose phosphate pathway and glycolysis in glioma stem-like cells. Acta Neuropathol 126: 763-780, 2013

53. Goidts V, Bageritz J, Puccio L, Nakata S, Zapatka M, Barbus S, Toedt G, Campos B, Korshunov A, Momma S, et al: RNAi screening in glioma stem-like cells identifies PFKFB4 as a key molecule important for cancer cell survival. Oncogene 31: 3235-3243, 2012

54. Jennings RT and Knaus UG: Rho family and Rap GTPase activation assays. Methods Mol Biol 1124: 79-88, 2014

55. Bejarano L, Schuhmacher AJ, Méndez M, Megías D, Blanco-Aparicio C, Martínez S, Pastor J, Squatrito M and Blasco MA: Inhibition of TRF1 telomere protein impairs tumor initiation and progression in glioblastoma mouse models and patient-derived xenografts. Cancer Cell 32: 590-607, 2017.

56. Huang W, Zhang C, Cui M, Niu J and Ding W: Inhibition of Bevacizumab-induced epithelial-mesenchymal transition by BATF2 overexpression involves the suppression of $\mathrm{Wnt} / \beta$-catenin signaling in glioblastoma cells. Anticancer Res 37: 4285-4294, 2017.

57. Iwadate Y: Epithelial-mesenchymal transition in glioblastoma progression. Oncol Lett 11: 1615-1620, 2016.

58. Clevers H, Loh KM and Nusse R: Stem cell signaling. An integral program for tissue renewal and regeneration: Wnt signaling and stem cell control. Science 346: 1248012, 2014

59. Takebe N, Miele L, Harris PJ, Jeong W, Bando H, Kahn M, Yang SX and Ivy SP: Targeting Notch, Hedgehog, and Wnt pathways in cancer stem cells: Clinical update. Nat Rev Clin Oncol 12: 445-464, 2015

60. Mohammed MK, Shao C, Wang J, Wei Q, Wang X, Collier Z, Tang S, Liu H, Zhang F, Huang J, et al: Wnt $/ \beta$-catenin signaling plays an ever-expanding role in stem cell self-renewal, tumorigenesis and cancer chemoresistance. Genes Dis 3: 11-40, 2016.

61. Lee J, Kee HJ, Min S, Park KC, Park S, Hwang TH, Ryu DH, Hwang GS and Cheong JH: Integrated omics-analysis reveals Wnt-mediated $\mathrm{NAD}^{+}$metabolic reprogramming in cancer stem-like cells. Oncotarget 7: 48562-48576, 2016.

62. Bae WJ, Lee SH, Rho YS, Koo BS and Lim YC: Transforming growth factor $\beta 1$ enhances stemness of head and neck squamous cell carcinoma cells through activation of Wnt signaling. Oncol Lett 12: 5315-5320, 2016.

63. Lee Y, Lee JK, Ahn SH, Lee J and Nam DH: WNT signaling in glioblastoma and therapeutic opportunities. Lab Invest 96: 137-150, 2016. 
64. Yu QC, Verheyen EM and Zeng YA: Mammary development and breast cancer: A Wnt perspective. Cancers 8: E65, 2016.

65. Koval AV, Vlasov P, Shichkova P, Khunderyakova S, Markov Y, Panchenko J, Volodina A, Kondrashov FA and Katanaev VL: Anti-leprosy drug clofazimine inhibits growth of triple-negative breast cancer cells via inhibition of canonical Wnt signaling. Biochem Pharmacol 87: 571-578, 2014.

66. Andersen V and Vogel U: Systematic review: Interactions between aspirin, and other nonsteroidal anti-inflammatory drugs, and polymorphisms in relation to colorectal cancer. Aliment Pharmacol Ther 40: 147-159, 2014.

67. Dovizio M, Tacconelli S, Sostres C, Ricciotti E and Patrignani P: Mechanistic and pharmacological issues of aspirin as an anticancer agent. Pharmaceuticals 5: 1346-1371, 2012.

68. Dovizio M, Bruno A, Tacconelli S and Patrignani P: Mode of action of aspirin as a chemopreventive agent. Recent Results Cancer Res 191: 39-65, 2013.

69. Sareddy GR, Kesanakurti D, Kirti PB and Babu PP: Nonsteroidal anti-inflammatory drugs diclofenac and celecoxib attenuates $\mathrm{Wnt} / \beta$-catenin/Tcf signaling pathway in human glioblastoma cells. Neurochem Res 38: 2313-2322, 2013.

70. Dharmapuri G, Doneti R, Philip GH and Kalle AM: Celecoxib sensitizes imatinib-resistant K562 cells to imatinib by inhibiting MRP1-5, ABCA2 and ABCG2 transporters via Wnt and Ras signaling pathways. Leuk Res 39: 696-701, 2015.

71. Lin XL, Xu Q, Tang L, Sun L, Han T, Wang LW and Xiao XY: Regorafenib inhibited gastric cancer cells growth and invasion via CXCR4 activated Wnt pathway. PLoS One 12: e0177335, 2017.

72. Tumova L, Pombinho AR, Vojtechova M, Stancikova J, Gradl D, Krausova M, Sloncova E, Horazna M, Kriz V, Machonova O, et al: Monensin inhibits canonical Wnt signaling in human colorectal cancer cells and suppresses tumor growth in multiple intestinal neoplasia mice. Mol Cancer Ther 13: 812-822, 2014.

73. Olmez I, Shen W, McDonald H and Ozpolat B: Dedifferentiation of patient-derived glioblastoma multiforme cell lines results in a cancer stem cell-like state with mitogen-independent growth J Cell Mol Med 19: 1262-1272, 2015.

74. Chen M, Wang J, Lu J, Bond MC, Ren XR, Lyerly HK, Barak LS and Chen W: The anti-helminthic niclosamide inhibits Wnt/Frizzled1 signaling. Biochemistry 48: 10267-10274, 2009.

75. Wieland A, Trageser D, Gogolok S, Reinartz R, Höfer H, Keller M, Leinhaas A, Schelle R, Normann S, Klaas L, et al: Anticancer effects of niclosamide in human glioblastoma. Clin Cancer Res 19: 4124-4136, 2013.

76. Arend RC, Londoño-Joshi AI, Samant RS, Li Y, Conner M, Hidalgo B, Alvarez RD, Landen CN, Straughn JM and Buchsbaum DJ: Inhibition of $\mathrm{Wnt} / \beta$ catenin pathway by niclosamide: A therapeutic target for ovarian cancer. Gynecol Oncol 134: 112-120, 2014.

77. Liu C, Lou W, Armstrong C, Zhu Y, Evans CP and Gao AC: Niclosamide suppresses cell migration and invasion in enzalutamide resistant prostate cancer cells via Stat3-AR axis inhibition. Prostate 75: 1341-1353, 2015.

78. Liu C, Lou W, Zhu Y, Nadiminty N, Schwartz CT, Evans CP and Gao AC: Niclosamide inhibits androgen receptor variants expression and overcomes enzalutamide resistance in castration-resistant prostate cancer. Clin Cancer Res 20: 3198-3210, 2014.

79. Londoño-Joshi AI, Arend RC, Aristizabal L, Lu W, Samant RS, Metge BJ, Hidalgo B, Grizzle WE, Conner M, Forero-Torres A, et al: Effect of niclosamide on basal-like breast cancers. Mol Cancer Ther 13: 800-811, 2014.

80. Liao Z, Nan G, Yan Z, Zeng L, Deng Y, Ye J, Zhang Z, Qiao M, Li R, Denduluri S, et al: The anthelmintic drug niclosamide inhibits the proliferative activity of human osteosarcoma cells by targeting multiple signal pathways. Curr Cancer Drug Targets 15: 726-738, 2015.

81. Lu W, Lin C, King TD, Chen H, Reynolds RC and Li Y: Silibinin inhibits Wnt/ $\beta$-catenin signaling by suppressing Wnt co-receptor LRP6 expression in human prostate and breast cancer cells. Cel Signal 24: 2291-2296, 2012.

82.Zhang X, Lou Y, Zheng X, Wang H, Sun J, Dong Q and Han B Wnt blockers inhibit the proliferation of lung cancer stem cells. Drug Des Devel Ther 9: 2399-2407, 2015.

83. Bryukhovetskiy IS, Mischenko PV, Tolok EV, Zaitcev SV, Khotimchenko YS and Bryukhovetskiy AS: Directional migration of adult hematopoeitic progenitors to C6 glioma in vitro. Oncol Lett 9: 1839-1844, 2015 .
84. Bryukhovetskiy IS, Dyuizen IV, Shevchenko VE, Bryukhovetskiy AS, Mischenko PV, Milkina EV and Khotimchenko YS: Hematopoietic stem cells as a tool for the treatment of glioblastoma multiforme. Mol Med Rep 14: 4511-4520, 2016.

85. Aboody KS, Brown A, Rainov NG, Bower KA, Liu S, Yang W Small JE, Herrlinger U, Ourednik V, Black PM, et al: Neural stem cells display extensive tropism for pathology in adult brain: Evidence from intracranial gliomas. Proc Natl Acad Sci USA 97: 12846-12851, 2000.

86. Aboody KS, Najbauer J, Metz MZ, D'Apuzzo M, Gutova M, Annala AJ, Synold TW, Couture LA, Blanchard S, Moats RA, et al: Neural stem cell-mediated enzyme/prodrug therapy for glioma: Preclinical studies. Sci Transl Med 5: 184ra59, 2013.

87. Aboody KS, Najbauer J, Schmidt NO, Yang W, Wu JK, Zhuge Y, Przylecki W, Carroll R, Black PM and Perides G: Targeting of melanoma brain metastases using engineered neural stem/ progenitor cell. Neuro Oncol 8: 119-126, 2006.

88. Gutova M, Najbauer J, Frank RT, Kendall SE, Gevorgyan A, Metz MZ, Guevorkian M, Edmiston M, Zhao D, Glackin CA, et al: Urokinase plasminogen activator and urokinase plasminogen activator receptor mediate human stem cell tropism to malignant solid tumors. Stem Cells 26: 1406-1413, 2008.

89. Kucia M, Reca R, Miekus K, Wanzeck J, Wojakowski W, Janowska-Wieczorek A, Ratajczak $\mathbf{J}$ and Ratajczak MZ: Trafficking of normal stem cells and metastasis of cancer stem cells involve similar mechanisms: Pivotal role of the SDF-1-CXCR4 axis. Stem Cells 23: 879-894, 2005.

90. Gabashvili AN, Baklaushev VP, Grinenko NF, Levinskii AB, Mel'nikov PA, Cherepanov SA and Chekhonin VP: Functionally active gap junctions between connexin 43-positive mesenchymal stem cells and glioma cells. Bull Exp Biol Med 159: 173-179, 2015.

91. Mercapide J, Rappa G and Lorico A: The intrinsic fusogenicity of glioma cells as a factor of transformation and progression in the tumor microenvironment. Int J Cancer 131: 334-43, 2012.

92.Rappa G, Mercapide J and Lorico A: Spontaneous formation of tumorigenic hybrids between breast cancer and multipotent stromal cells is a source of tumor heterogeneity. Am J Pathol 180 2504-2515, 2012.

93. Mercapide J, Anzanello F, Rappa G and Lorico A: Relationship between tumor cell invasiveness and polyploidization. PLoS One 7: e53364, 2012.

94.Zimmerlin L, Park TS, Zambidis ET, Donnenberg VS and Donnenberg AD: Mesenchymal stem cell secretome and regenerative therapy after cancer. Biochimie 95: 2235-2245, 2013.

95. O'Donnell RK, Falcon B, Hanson J, Goldstein WE, Perruzzi C Rafii S, Aird WC and Benjamin LE: VEGF-A/VEGFR inhibition restores hematopoietic homeostasis in the bone marrow and attenuates tumor growth. Cancer Res 76: 517-524, 2016.

96. Hong JP, Li XM, Li MX and Zheng FL: VEGF suppresses epithelial-mesenchymal transition by inhibiting the expression of Smad3 and miR-192, a Smad3-dependent microRNA. Int J Mol Med 31: 1436-1442, 2013.

97. Treps L, Perret R, Edmond S, Ricard D and Gavard J: Glioblastoma stem-like cells secrete the pro-angiogenic VEGF-A factor in extracellular vesicles. J Extracell Vesicles 6: 1359479, 2017.

98. Diaz RJ, Ali S, Qadir MG, De La Fuente MI, Ivan ME and Komotar RJ: The role of bevacizumab in the treatment of glioblastoma. J Neurooncol 133: 455-467, 2017.

99. Bryukhovetskiy I,Lyakhova I, Mischenko P,Milkina E,Zaitsev S, Khotimchenko Y, Bryukhovetskiy A, Polevshchikov A, Kudryavtsev I, Khotimchenko M, et al: Alkaloids of fascaplysin are effective conventional chemotherapeutic drugs, inhibiting the proliferation of C6 glioma cells and causing their death in vitro. Oncol Lett 13: 738-746, 2017.

100. Pacioni S, D'Alessandris QG, Giannetti S, Morgante L, Coccè V, Bonomi A, Buccarelli M, Pascucci L, Alessandri G, Pessina A, et al: Human mesenchymal stromal cells inhibit tumor growth in orthotopic glioblastoma xenografts. Stem Cell Res Ther 8: 53, 2017.

101. Bryukhovetskiy I, Bryukhovetsky A, Khotimchenko Y, Mischenko P, Tolok E and Khotimchenko R: Combination of the multipotent mesenchymal stromal cell transplantation with administration of temozolomide increases survival of rats with experimental glioblastoma. Mol Med Rep 12: 2828-2834, 2015.

102. English K: Mesenchymal stem cells to promote islet transplant survival. Curr Opin Organ Transplant 21: 568-573, 2016. 
103. Vizoso FJ, Eiro N, Cid S, Schneider J and Perez-Fernandez R Mesenchymal stem cell secretome: Toward cell-free therapeutic strategies in regenerative medicine. Int J Mol Sci 18: E1852, 2017.

104. Katakowski M and Chopp M: Exosomes as tools to suppress primary brain tumor. Cell Mol Neurobiol 36: 343-352, 2016.

105. Liu X, Li Q, Niu X, Hu B, Chen S, Song W, Ding J, Zhang C and Wang Y: Exosomes secreted from human-induced pluripotent stem cell-derived mesenchymal stem cells prevent osteonecrosis of the femoral head by promoting angiogenesis. Int J Biol Sci 13: 232-244, 2017.

106. Klopp AH, Gupta A, Spaeth E, Andreeff M and Marini F III: Concise review: Dissecting a discrepancy in the literature: Do mesenchymal stem cells support or suppress tumor growth? Stem Cells 29: 11-19, 2011.

107. Alcayaga-Miranda F, González PL, Lopez-Verrilli A, Varas-Godoy M, Aguila-Díaz C, Contreras L and Khoury M: Prostate tumor-induced angiogenesis is blocked by exosomes derived from menstrual stem cells through the inhibition of reactive oxygen species Oncotarget 7: 44462-44477, 2016.

108. Bliss SA, Sinha G, Sandiford OA, Williams LM, Engelberth DJ, Guiro K, Isenalumhe LL, Greco SJ, Ayer S, Bryan M, et al: Mesenchymal stem cell-derived exosomes stimulate cycling quiescence and early breast cancer dormancy in bone marrow. Cancer Res 76: 5832-5844, 2016.

109. Reza AM, Choi YJ, Yasuda H and Kim JH: Human adipose mesenchymal stem cell-derived exosomal-miRNAs are critical factors for inducing anti-proliferation signalling to A2780 and SKOV-3 ovarian cancer cells. Sci Rep 6: 38498, 2016.

110. Baglio SR, Rooijers K, Koppers-Lalic D, Verweij FJ, Pérez Lanzón M, Zini N Naaijkens B, Perut F, Niessen HW Baldini $\mathrm{N}$ and Pegtel DM: Human bone marrow- and adipose-mesenchymal stem cells secrete exosomes enriched in distinctive miRNA and tRNA species. Stem Cell Res Ther 6: 127,2015

111. Lopatina T, Gai C, Deregibus MC, Kholia S and Camussi G: Cross talk between cancer and mesenchymal stem cells through extracellular vesicles carrying nucleic acids. Front Oncol 6: 125 , 2016.

112. Zhang Z, Gong Q, Li M, Xu J, Zheng Y, Ge P and Chi G: MicroRNA-124 inhibits the proliferation of C6 glioma cells by targeting Smad4. Int J Mol Med 40: 1226-1234, 2017.

113. Mei LL, Wang WJ, Qiu YT, Xie XF, Bai J and Shi ZZ: miR-145-5p suppresses tumor cell migration, invasion and epithelial to mesenchymal transition by regulating the $\mathrm{Sp} 1 / N F-\kappa B$ signaling pathway in esophageal squamous cell carcinoma. Int J Mol Sci 18: E1833, 2017.

114. Gong Y, Qin Z, Zhou B, Chen H, Shi Z and Zhang J: MicroRNA-200a inhibits transforming growth factor $\beta 1$-induced proximal tubular epithelial-mesenchymal transition by targeting $\beta$-Catenin. Nephron 137: 237-249, 2017.

115. Yan J, Jiang JY, Meng XN, Xiu YL and Zong ZH: MiR-23b targets cyclin G1 and suppresses ovarian cancer tumorigenesis and progression. J Exp Clin Cancer Res 35: 31, 2016.

116. Liu G, Xu Z and Hao D: MicroRNA-451 inhibits neuroblastoma proliferation, invasion and migration by targeting macrophage migration inhibitory factor. Mol Med Rep 13. 2253-2260, 2016.

117. Zeng T, Peng L, Chao C, Fu B, Wang G, Wang Y and Zhu X: miR-451 inhibits invasion and proliferation of bladder cancer by regulating EMT. Int J Clin Exp Pathol 7: 7653-7662, 2014.

118. Xu H, Mei Q, Shi L, Lu J, Zhao J and Fu Q: Tumor-suppressing effects of miR451 in human osteosarcoma. Cell Biochem Biophys 69: 163-168, 2014.
119. Ji Q, Hao X, Zhang M, Tang W, Yang M, Li L, Xiang D, Desano JT, Bommer GT, Fan D, et al: MicroRNA miR-34 inhibits human pancreatic cancer tumor-initiating cells. PLoS One 4: e6816, 2009.

120. Alvarado AG, Thiagarajan PS, Mulkearns-Hubert EE, Silver DJ, Hale JS, Alban TJ, Turaga SM, Jarrar A, Reizes O, Longworth MS, et al: Glioblastoma cancer stem cells evade innate immune suppression of self-renewal through reduced TLR4 expression. Cell Stem Cell 20: 450-461.e4, 2017.

121. Sathyanarayanan A, Chandrasekaran KS and Karunagaran D: microRNA-145 downregulates SIPI-expression but differentially regulates proliferation, migration, invasion and Wnt signalling in SW480 and SW620 cells. J Cell Biochem 119: 2022-2035, 2018.

122. Sathyanarayanan A, Chandrasekaran KS and Karunagaran D: microRNA-145 modulates epithelial-mesenchymal transition and suppresses proliferation, migration and invasion by targeting $S I P 1$ in human cervical cancer cells. Cell Oncol 40: 119-131, 2017.

123. Katakowski M, Buller B, Zheng X, Lu Y, Rogers T, Osobamiro O, Shu W, Jiang F and Chopp M: Exosomes from marrow stromal cells expressing miR-146b inhibit glioma growth. Cancer Lett 335: 201-204, 2013.

124. Gopal SK, Greening DW, Rai A, Chen M, Xu R, Shafiq A, Mathias RA, Zhu HJ and Simpson RJ: Extracellular vesicles: Their role in cancer biology and epithelial-mesenchymal transition. Biochem J 474: 21-45, 2017.

125. Ti D, Hao H, Fu X and Han W: Mesenchymal stem cells-derived exosomal microRNAs contribute to wound inflammation. Sci China Life Sci 59: 1305-1312, 2016.

126. Hambardzumyan D, Gutmann DH and Kettenmann H: The role of microglia and macrophages in glioma maintenance and progression. Nat Neurosci 19: 20-27, 2016.

127. Wang Y, Liu T, Yang N, Xu S, Li X and Wang D: Hypoxia and macrophages promote glioblastoma invasion by the CCL4-CCR5 axis. Oncol Rep 36: 3522-3528, 2016.

128. Kondo Y, Katsushima K, Ohka F, Natsume A and Shinjo K: Epigenetic dysregulation in glioma Cancer Sci 105: 363-369, 2014.

129. Feng X, Szulzewsky F, Yerevanian A, Chen Z, Heinzmann D, Rasmussen RD, Alvarez-Garcia V, Kim Y, Wang B, Tamagno I, et al: Loss of CX3CR1 increases accumulation of inflammatory monocytes and promotes gliomagenesis. Oncotarget 6: 15077-15094, 2015.

130. Nusblat LM, Carroll MJ and Roth CM: Crosstalk between M2 macrophages and glioma stem cells. Cell Oncol 40: 471-482, 2017.

131. Zhou W, Ke SQ, Huang Z, Flavahan W, Fang X, Paul J, Wu L, Sloan AE, McLendon RE, Li X, et al: Periostea secreted by glioblastoma stem cells recruits $\mathrm{M} 2$ tumour-associated macrophages and promotes malignant growth. Nat Cell Biol 17: $170-182,2015$

132. Alifieris C and Trafalis DT: Glioblastoma multiforme: Pathogenesis and treatment. Pharmacol Ther 152: 63-82, 2015.

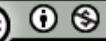

This work is licensed under a Creative Commons Attribution-NonCommercial 4.0 International (CC BY-NC 4.0) License. 